\title{
Como são avaliados os candidatos para obtenção de graus acadêmicos e cargos docentes?
}

\author{
Osvaldo Malafaia*, Jurandir Marcondes Ribas Filho*, Nicolau Gregori Czeczko*, Ulrich Andreas Dietz* \\ *Professores permanentes doutores do Programa de Pós-Graduação em Princípios da Cirurgia do Hospital Universitário Evangélico de Curitiba/ \\ Faculdade Evangélica do Paraná, Curitiba-PR, Brasil.
}

A vida do profissional da grande área da saúde - e em especial da medicina - tem sofrido elevação de paradigmas, quando se comparam pares na escolha do melhor candidato para cargos e funções. Se olharmos o passado a médio prazo e fazendo-se projeção para futuro próximo, podemos prever o que nos espera, e, inteligentemente, devemos procurar incorporar em nossa formação as exigências previstas, antecipando-nos a elas. Porque assim é, e continuará sendo? A resposta é simples: há maior oferta de candidatos; candidatos melhor preparados competindo entre si; elevação do grau de exigência da formação com que a sociedade conceitua as profissões da grande área.

Já se foi o tempo onde somente a graduação contava. Logo veio o primeiro degrau na formação da vida do médico: a residência - que agora está sendo criada e será exigida em outras profissões da área da saúde. Ter sido residente por dois anos era um grande diferencial no passado. Hoje ela é de mais anos, na dependência da especialidade e, pior, somente a residência não tem mais sido diferenciação entre candidatos. Há cerca de 20 anos, era o mestrado após a residência o paradigma da boa formação. A ele foi rapidamente adicionado o grau de doutor e, parece, que o futuro poderá usar o pós-doutorado como diferencial.

Dirão os menos avisados: complicaram nossa vida! Sob certo aspecto, sim. O tempo para estar-se pronto para competir com chance de ganhar aumentou muito e, com ele, as dificuldades de ser encontrado lugar certo para conseguir-se a formação necessária, e arcar com as conseqüentes despesas. Por outro aspecto, não! O Brasil está diferente de períodos anteriores e quem não se apercebeu disto, está ficando para trás. Nosso país está internacionalizando-se e com isso, os paradigmas de qualificação dos recursos humanos existentes há muitos anos nos países desenvolvidos, estão sendo importados para nós, tal como ocorreu e ocorre com o desenvolvimento tecnológico e o crescimento econômico. Crescemos sim e, muito mais, pretendemos deixar de ser país em desenvolvimento. É o que está ocorrendo com a nossa economia. Quem há poucos anos poderia acreditar que seríamos país com grau de investimento internacional, que estamos prestes a conseguir. O que significa isso? Que ele está arrumado economicamente e compara-se a outros do primeiro mundo neste aspecto. Assim, porque não ser equivalentes a outros países nos graus de exigência da capacitação de seus recursos humanos? É o que estamos presenciando nos dias de hoje e por isso há necessidade de, quem quiser viver bem o futuro, preparar-se para ele.

A vida acadêmica é apaixonante e cremos que esta paixão reside no coração da quase totalidade dos profissionais envolvidos na assistência. Ela (a assistência) pura ao longo do tempo pode ficar monótona. A ausência de algo maior, ou seja, a criação de alternativas - que sempre temos em nossa mente para melhorar o atendimento prestado -, pode ser frustrante. Assim, a vida acadêmica é a vontade interior constante de crescimento para aqueles que se prestam ao atendimento à saúde. E o momento atual, com a criação exagerada de cursos de graduação em todas as áreas, faz com que oportunidades para a docência e pesquisa se engrandeçam. Mas, um fato é inegável: as oportunidades chegam somente para aqueles que estão prontos, ou seja, para os que acreditaram que o futuro seria diferente e se prepararam para ele.

Dessa forma a aquisição dos graus acadêmicos deve antecipar o ingresso incerto, mas possível, na carreira docente. O grau de mestre forma o profissional nas bases da pesquisa e docência. É fase preparatória onde a didática, o método e sua habilidade de manuseio é o que valem. Já no doutorado, a demonstração de que determinada idéia com grau de originalidade aplicada pode melhorar o existente, é o que se mensura. A estes graus está sendo valorizado atualmente o pósdoutorado, que nada mais é que o aprofundamento do que foi feito no doutorado, agora olhando-se em sua aplicabilidade prática onde os resultados satisfatórios possam auxiliar a assistência à saúde. Na livre-docência - somente obtida em algumas universidades federais e estaduais por concursos abertos em editais especiais -, é possível somente aos portadores do grau de doutor. Exige-se, através de publicações seqüenciais durante anos, que o candidato ao título tenha linha de pesquisa bem definida - preferencialmente iniciada no doutorado, continuada no pós-doutorado e em sua vida acadêmica -, e que tenha contribuição efetiva no assunto que escolheu estudar.

A carreira docente, referindo-se somente ao sistema federal de ensino, corre paralela e, para progressão funcional, dependente da obtenção dos graus acadêmicos. Ela é estratificada em dois segmentos. O primeiro, que vai do professor auxiliar (especialista), passando pelo professor assistente (mestre) e terminando no professor adjunto/associado (doutor), 
é de progressão vertical, ou seja, chega-se a ele desde que o candidato, ou já funcionário, apresente os graus acadêmicos referentes ao nível. O segundo, o de professor titular, tem concurso próprio e a inscrição a ele somente é permitida aos portadores do grau de doutor obtido em programas de pósgraduação recomendados pela CAPES, ou título de livredocente, podendo o candidato já ser professor da instituição ou não. A intenção de oportunizar a entrada de candidato externo, é tentar quebrar a endogenia acadêmica, muito comum na universidade, dando oportunidade a pessoas externas que apresentem idéias e dinâmica novas a possibilidade de mudança o status quo.

Os concursos da carreira docente e exames de defesa de tese são regulamentados no Brasil e semelhantes aos realizados em vários outros países. De regra, a banca examinadora é composta por pelo menos $1 / 3$ de professores externos à instituição, o que dá pelo menos um para as bancas de três membros (mestrado,) e dois nas de cinco (cargos da carreira docente, doutorado, livre-docência). Todos os membros devem possuir no mínimo o título do concurso em questão. de concurso.

As bancas comportam- se diferentemente em cada tipo

$\mathrm{O}$ que se espera que o candidato apresente nos seus vários tipos?

No mestrado procura-se verificar se ele adquiriu conhecimentos de metodologia científica e aplicou-a corretamente na sua pesquisa. Além disso, se adquiriu capacitação docente para o nível superior, demonstrada em uma sessão pública. No doutorado, não só o referido no mestrado, mas também a demonstração científica da aplicabilidade e originalidade da proposta da pesquisa desenvolvida. Na livredocência, realizada em cinco provas, duas reservadas - prática e escrita -, e três públicas - didática, defesa de tese e defesa de memorial -, conta muito a experiência em anos de trabalho com a linha de pesquisa que, preferencialmente, tenha-se iniciado no doutorado com resultados desta dedicação, demonstrada por trabalhos publicados em revistas de impacto. Para este último grau acadêmico, na defesa do memorial, onde o candidato apresenta sua vida desde a formação acadêmica, passando pela experiência acadêmica e produção intelectual, as publicações que fez em sua vida contam muito.

Já nos concursos da carreira docente as provas, embora diversas na dependência da universidade, centralizam-se na didática e defesa do memorial. O que motiva muita controvérsia é o comportamento da banca que, não infreqüentemente, indica um candidato diferente do esperado pela comunidade para aquele cargo. Porque isso acontece?

A razão é simples. No primeiro segmento supra referido (professor auxiliar, assistente e adjunto/associado), considerando-se a progressão funcional, procura-se ver se o candidato ao nível superior ao que está, cumpriu seu papel no exercício do cargo anterior, ou seja, ao candidato a assistente, se fez mestrado, deu aulas regularmente, exerceu atividades técnicas para divulgação de seu trabalho acadêmico e publicou com regularidade. Para o cargo de adjunto/associado, tudo o que se referiu como necessário ao assistente, contudo ampliado, adicionado de prática administrativa que o fará candidato fu- turo a professor titular. Para o professor titular, com certeza a demonstração cabal da prática acadêmica, tanto em aulas como em gestão, somada à experiência de administração pública, são requisitos fortemente valorizados. Contudo, à esta fundamental base, associa-se o que efetivamente faz a diferença: a publicação científica.

Assim sendo, fica mais fácil de ser entendido o comportamento das bancas que, através do memorial apresentado, analisam e contabilizam esses dados. Com certa freqüência, um candidato a professor titular apresenta seu memorial com ênfase quase exclusiva na publicação, esquecendose que a didática e gestão são necessárias ao cargo. Confundem o cargo de professor titular com o de pesquisador, sendo que neste sim, a publicação é o que unicamente determina a escolha. $\mathrm{Ou}$, o candidato compreendendo que a docência e gestão são importantes ao cargo, diminui o valor da pesquisa e é surpreendido pelo resultado onde este último aspecto foi valorizado na concorrência, até então equalitária entre os postulantes.

Assim, o ingresso na carreira é de pouca exigência especialização, alguma experiência docente e a publicação que houver. Na evolução a professor assistente, obriga-se mestrado, maior participação na docência, início de gestão na área e atividade intelectual maior (publicações e atividades técnicas conferências, mesas redondas, simpósios e outras). Para adjunto/ associado, o referido ao assistente, contudo, com maior relevância tanto em número, quanto em qualidade. Para o titular, tudo o que se falou ao adjunto/associado e, aqui sim, publicações mais numerosas, de alto nível, tanto quanto aos periódicos onde estão publicadas, como nas mensagens científicas transmitidas.

Os editais que abrem os concursos, de modo geral, quantificam o peso que cada prova tem, no contexto final da média classificatória, ou, se não, os regimentos universitários versam detalhes sobre o assunto. No entanto, a produção intelectual é a que faz a diferença e normalmente a que define a indicação do melhor candidato.

Quando se fala em produção intelectual citam-se: 1) as atividades técnicas, obtidas em apresentações em congressos e outros eventos científicos, e que mostram a boa inserção do candidato no cenário nacional/internacional, o respeito e o interesse dos seus pares pela sua atuação científica, e 2) publicações, que merecem menção e destaque especial. Elas estão sendo cada vez mais rigorosamente analisadas, porque, o mundo mudou e nós mudamos! O referencial máximo internacional para qualificação da produção científica publicada é o Journal of Citaton Report - JCR, editado pela International Scientific Information - ISI ${ }^{1}$. O que ele faz? Em trabalho hercúleo ${ }^{2}$, contabiliza, em quantidade individualizada por periódico, o número de vezes que as revistas que integram a base ISI são citadas nas referências de todos os artigos impressos. A seguir, estabelece classificação delas e a expõe na internet. $\mathrm{O}$ índice baseado nas citações que a revista teve nos dois últimos anos, é chamado fator de impacto, um dos fatores ofertados pelo JCR e o principal elemento usado na análise qualitativa das revistas científicas. A sua interpretação deve ser criteriosa, pois, nas comparações que se fizerem, há necessidade 
de se estabelecer o universo procurado. Assim, na busca de revistas que abordem cirurgia do aparelho digestivo não se deve comparar com outras gerais. Por exemplo, o New England Journal of Medicine, que é periódico geral da medicina com fator de impacto alto, deve ser comparado com o Lancet, British Journal of Medicine, JAMA e outros que são da mesma área de abrangência. Ou seja, há necessidade de setorizar a busca, individualizando-se a área o quanto permitido pelo JCR, e aí sim, na comparação ter-se-á a exata noção da posição classificatória da revista que buscamos, e seu fator de impacto comparado com as similares.

Como a base ISI está quase saturada, há muita dificuldade de novos títulos serem incorporados. Com isso, a alternativa brilhante da BIREME foi criar a $\mathrm{SciELO}^{2}$ (Scientific Eletronic Library Online conectada ao Pubmed desde 1999) com o apoio da FAPESP e OMS. Ela é hoje considerada uma das principais bases de visibilidade bibliográfica mundial, tendo aceitação global. Pretende em breve futuro, classificar as revistas nela incorporadas, oferecendo fator de impacto (e outros) da literatura científica brasileira. Outros países hispânicos já estão sendo integrados nela, mostrando a pujança de sua atuação na literatura científica, fora do eixo do primeiro mundo. As dificuldades para indexação na SciELO são muito grandes, e não poderia ser diferente se quisermos ter respeitabilidade internacional. Assim, os periódicos nela incluídos têm maior valor e, conseqüentemente, as publicações dos autores passam a ser mais importantes e mais competitivas.

Na avaliação da produção bibliográfica dos programas de pós-graduação stricto sensu, a CAPES criou o Qualis ${ }^{3}$. A intenção inicial não era - e ainda não é - a de hierarquizar periódicos, e sim, saber com critérios por ela estabelecidos, qual o nível de produção científica dos programas e, principalmente com base nele, conceituá-los entre notas 3 e 7 . Dividiu-o em Qualis A, B e C nacional e A, B e C internacional. Assim, para um periódico ser A nacional uma das possibilidades é estar incluído na SciELO e para ingressar no Qualis internacional, estar no Medline/Pubmed é o principal meio.

Frente ao exposto é mais fácil de entender-se porque o número de publicações em um memorial não é fator que indica o escolhido e sim a qualidade. Freqüentemente em concursos, os candidatos não entendem porque uma centena de publicações às vezes perde para poucas dezenas. É o valor intrínseco das revistas onde estão inseridas suas publicações - quantidade não é qualidade! Como por exemplo, hipoteticamente um candidato que tenha 60 publicações distribuídas entre 30 Lilacs (Qualis B nacional), 20 não indexadas (Qualis C nacional) e 10 SciELO (Qualis A nacional) pode perder para outro que apresente 20 publicações Medline (Qualis C ou maior internacional). Universidades quando remetem os memoriais para análise dos membros da banca têm muitas vezes enviado junto indicativos de pontuação na classificação dos periódicos das grandes bases e também do Qualis.

Onde se enquadra a ACTA CIRÚRGICA BRASILEIRA neste contexto?

Ela, por estar na SciELO desde 1997 era qualificada como Qualis A nacional. A partir de 2005 foi incorporada no Medline/Pubmed e assim passou a categoria de periódico internacional, e subiu para Qualis C internacional. É grande orgulho para nosso país porque somente nove são as revistas médicas brasileiras, com conexão de contexto com a área cirúrgica, incluídas no Medline/Pubmed.

Recentemente tivemos o grande prazer de vê-la incluída na International Scientific Information - ISI sendo o único periódico nacional específico da área cirúrgica nesta categoria, o que a coloca ainda mais dentro dos padrões de qualidade internacional.

Assim, como mensagem final aos leitores sugerimos que PUBLIQUEM SEUS ARTIGOS NA ACTA CIRÚRGICA BRASILEIRA, pois, em concursos futuros, seus trabalhos valerão mais. Talvez nessa época lembrar-se-ão que ter lido este editorial, o ajudou e valeu a pena!

\section{Referências}

1. http://scientific.thomson.com/es/productos/evaluacion/jcrport/ ou isinet.com ou www.scientific.thomson.com/support/products/jer

2.www.scielo.br, e-mail: scielo@bireme.br

3. www.capes.gov.br/avaliacao/webqualis.html

\section{Correspondência:}

Prof. Osvaldo Malafaia

R. Helly de Macedo Souza, 33

82520-390 Curitiba - PR Brasil

malafaia@evangelico.org.br 